\title{
Anti-flavin antibodies
}

\author{
Michael J. BARBER, ${ }^{*} \ddagger$ Duane C. EICHLER, ${ }^{*}$ Larry P. SOLOMONSON* and Brian A. ACKRELL $\dagger$ \\ *Department of Biochemistry, University of South Florida College of Medicine, Tampa, FL 33612, U.S.A., \\ and $\uparrow$ Department of Biochemistry and Biophysics, University of California, San Francisco, CA 94143, U.S.A.
}

\begin{abstract}
Antibodies were elicited to FAD by using the hapten $N-6-(6$-aminohexyl)-FAD conjugated to the immunogenic carrier protein bovine serum albumin. Cross-reactivity was determined by Ouchterlony double-diffusion analysis with $N$-6-(6-aminohexyl)-FAD coupled to rabbit serum albumin. Anti-FAD IgG was partially purified by $\left(\mathrm{NH}_{4}\right)_{2} \mathrm{SO}_{4}$ precipitation followed by DEAE-cellulose/CM-cellulose and bovine serum albumin-agarose chromatography. The partially purified anti-FAD IgG fraction failed to inhibit the catalytic activities of the flavin-containing enzymes nitrate reductase, xanthine oxidase and succinate dehydrogenase, whereas enzyme activity could be inhibited by addition of antibodies elicited against the native proteins. However, the partially purified anti-FAD IgG fraction could be used as a highly sensitive and specific probe to detect proteins containing only covalently bound flavin, such as succinate dehydrogenase, $p$-cresol methylhydroxylase and monoamine oxidase, by immuno-blotting techniques. Detection limits were estimated to be of the order of femtomolar concentrations of FAD with increased sensitivity for the $8 \alpha-N(3)$-histidyl linkage compared with $8 \alpha-O$-tyrosyl substitution.
\end{abstract}

\section{INTRODUCTION}

Although antibodies are frequently used for the detection and characterization of macromolecules (Van Vunakis \& Langone, 1980), techniques have been developed to enable antibodies to be elicited against low- $M_{\mathrm{r}}$ haptens covalently linked to suitable immunogens such as BSA and haemocyanin (Kovac et al., 1985; Humphries \& McConnell, 1976). The availability of antibodies elicited against a specific prosthetic group of an enzyme could facilitate their use both for the detection and localization of the enzyme, as well as other proteins bearing the same prosthetic group, in addition to possible use of the antibodies as site-specific inhibitors. (In complex redox enzymes containing a variety of different, independent, prosthetic groups, antibodies could prove to be inhibitors of extremely high specificity and affinity, potentially useful for delineating electron-transfer sequences.) In addition, antibodies directed against specific prosthetic groups could be utilized to provide topographical information concerning the structure of the enzyme, such as the subunit or polypeptide chain associated with the chromophore, as well as accessibility and information concerning prosthetic-group synthesis, modification and insertion.

The present paper describes the preparation and characterization of antibodies elicited against the FAD molecule, their use in identifying the location of covalently bound flavin chromophores within enzyme subunits and their application as a highly sensitive detection method for complex heterogeneous samples.

\section{MATERIALS AND METHODS}

\section{Materials}

BSA (fraction V, essentially fatty acid-free), RSA (fraction V), complete and incomplete Freund's adjuvant, phenazine methosulphate and 2,6-dichlorophenol-indo- phenol were purchased from Sigma Chemical Co. HAWP nitrocellulose filters $(2.4 \mathrm{~cm} ; 0.45 \mu \mathrm{m}$ pore size $)$ were purchased from Millipore. DEAE-cellulose DE-52 and CM-cellulose CM-52 were obtained from Whatman. The immuno-blot assay kit containing goat anti-(rabbit IgG) antibody-horseradish peroxidase conjugate and nitrocellulose membrane $(0.45 \mu \mathrm{m}$ pore size $)$ were purchased from Bio-Rad Laboratories. 6-AH-FAD was provided by, and is proprietary to, Miles Laboratories, and was synthesized by the procedure described by Morris \& Buckler (1983).

\section{Methods}

Coupling of 6-AH-FAD to BSA. 6-AH-FAD was conjugated to BSA with the use of the coupling agent dimethyl adipimidate as described by Morris \& Buckler (1983). The number of molecules of 6-AH-FAD conjugated per molecule of BSA was estimated in the following manner. The protein concentration of the conjugate sample was determined by the method of Lowry et al. (1951) and the concentration of 6-AH-FAD was determined from the visible-region spectrum of the conjugate sample by using an absorption coefficient of $11.3 \mathrm{~mm}^{-1} \cdot \mathrm{cm}^{-1}$ at $450 \mathrm{~nm}$ (Whitby, 1953). The ratio of the molar concentrations of 6-AH-FAD and protein gave the number of conjugated flavin residues per albumin molecule.

6-AH-FAD was conjugated to RSA by a similar procedure and purified by column chromatography on Sephadex G-25 equilibrated with 0.1 M-sodium phos-

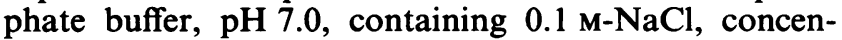
trated and characterized as for the BSA-6AH-FAD complex.

Immunization and antiserum preparation. Procedures used in the production of antisera to the albumin6-AH-FAD conjugate were as described previously by Eichler \& Glitz (1974). A $1 \mathrm{mg}$ portion of conjugate 


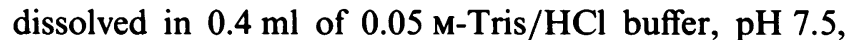
containing $0.1 \mathrm{M}-\mathrm{NaCl}$ and $0.1 \mathrm{~mm}$-EDTA was mixed with $1.6 \mathrm{ml}$ of complete Freund's adjuvant to form a uniform homogenate. Approx. $0.1 \mathrm{ml}$ of this homogenate was injected into each toe-pad of a 3-month-old New Zealand White rabbit. After 2 weeks the rabbit was injected subcutaneously in the hindquarters with $0.5 \mathrm{mg}$ of conjugate in $0.1 \mathrm{ml}$ of buffer and mixed with $0.4 \mathrm{ml}$ of incomplete Freund's adjuvant. At 4 weeks from the time of the initial injection, blood was collected from the ear vein, and the serum was tested by double diffusion on agar plates (Ouchterlony, 1968). Subsequently, at intervals of 7-8 days, the rabbit was bled from the ear vein, the blood was allowed to clot, and the serum was removed and clarified by centrifugation at $2000 \mathrm{~g}$. The clarified serum was either processed for preparation of an IgG protein fraction or stored frozen at $-70^{\circ} \mathrm{C}$. Similar procedures were used to elicit antibodies to purified nitrate reductase and xanthine oxidase.

Purification of $\gamma$-globulin. Preparation of IgG fraction from whole serum was carried out as described by Palacios et al. (1972). Antiserum (10 ml) was diluted with an equal volume of $0.05 \mathrm{M}$-Tris/ $\mathrm{HCl}$ buffer, $\mathrm{pH} 7.5$, containing $0.1 \mathrm{M}-\mathrm{NaCl}$ and $0.1 \mathrm{~mm}$-EDTA. At $0{ }^{\circ} \mathrm{C}$, $4.52 \mathrm{~g}$ of solid $\left(\mathrm{NH}_{4}\right)_{2} \mathrm{SO}_{4}$ was added slowly until $40 \%$ saturation was achieved. After $30 \mathrm{~min}$ the precipitate was collected by centrifugation at $20000 \mathrm{~g}$ for $15 \mathrm{~min}$. The pellet was dissolved in $4 \mathrm{ml}$ of $0.01 \mathrm{M}$-sodium phosphate buffer, $\mathrm{pH} 7.2$, containing $0.015 \mathrm{M}-\mathrm{NaCl}$ and dialysed overnight against this same buffer. The dialysed sample was clarified by centrifugation, and applied to a DEAE-cellulose/CM-cellulose column $(1.5 \mathrm{~cm} \times 10 \mathrm{~cm})$ that contained $5 \mathrm{~cm}$ of DEAE-cellulose overlayed with $5 \mathrm{~cm}$ of CM-cellulose, both equilibrated against $0.01 \mathrm{M}$ sodium phosphate buffer, pH 7.2, containing $0.015 \mathrm{M}-\mathrm{NaCl}$. The flow-through fractions were pooled and concentrated by vacuum dialysis against $0.05 \mathrm{M}$ -

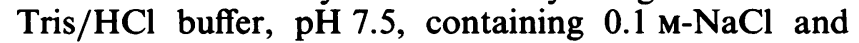
$0.1 \mathrm{~mm}$-EDTA. The IgG fraction was further purified by passage through a BSA-agarose affinity column prepared by coupling BSA to CNBr-activated agarose in $0.05 \mathrm{M}$-sodium phosphate buffer, $\mathrm{pH} 7.2$, to remove anti-BSA IgG.

Immunodiffusion. Double diffusion (Ouchterlony, 1968) was run in $1 \%$ agar made up in $0.05 \mathrm{M}$-Tris/HCl buffer, $\mathrm{pH} 7.5$, containing $0.1 \mathrm{M}-\mathrm{NaCl}$ and $0.1 \mathrm{~mm}-$ EDTA. Standard antigen solutions were $1 \mathrm{mg} / \mathrm{ml}$ unless otherwise specified. Serum was placed in the centre well, and antigen in the outer wells. Development was allowed to take place overnight at room temperature. The immunodiffusion plates were then washed overnight in $0.9 \% \mathrm{NaCl}$, rinsed with distilled water, and dried in a hood after being covered with a moist strip of filter paper. Once the plates were completely dry, the filter-paper strip was removed and the plates were stained with $0.6 \%$ Amido Black suspended in destaining solution (methanol/water/acetic acid, 5:5:1, by vol.) followed by washing with distilled water, and subsequent destaining for $15 \mathrm{~min}$.

Enzyme preparation. Succinate dehydrogenase was purified from bovine heart mitochondria as described by Baginsky \& Hatefi (1969). NADH-linked nitrate reductase was purified to electrophoretic homogeneity from
Chlorella vulgaris as previously described (Howard \& Solomonson, 1982). Xanthine oxidase was isolated from bovine milk as described by Barber \& Siegel (1982).

Enzyme assays. Succinate dehydrogenase activity was determined as described by Hatefi (1978) with succinate, 2,6-dichlorophenol-indophenol and phenazine methosulphate. Nitrate reductase activity was determined as the NADH-dependent reduction of $\mathrm{NO}_{3}{ }^{-}$as previously described (Solomonson et al., 1975). Xanthine oxidase activity was monitored at $295 \mathrm{~nm}$ by using the aerobic formation of uric acid from xanthine (Avis et al., 1955). For the inhibition assays, purified enzyme was incubated with the desired volume of purified IgG fraction in 0.05 M-sodium phosphate buffer, $\mathrm{pH} \mathrm{7.8,} \mathrm{containing}$ $0.1 \mathrm{M}-\mathrm{NaCl}$ and $0.1 \mathrm{~mm}$-EDTA for $2 \mathrm{~min}$ at $25^{\circ} \mathrm{C}$ and the assay was initiated by the addition of either substrate or acceptor. Control enzyme samples in the absence of the IgG fraction were subjected to identical treatments.

SDS/polyacrylamide-gel electrophoresis. Proteins were separated by SDS/polyacrylamide-slab-gel electrophoresis on linear gradients of $7.5-15 \%$ polyacrylamide with the buffer system described by Laemmli (1970). The $M_{\mathrm{r}}$ standards (BRL Laboratories) used were myosin $\left(M_{\mathrm{r}}\right.$ $205000)$, phosphorylase $b\left(M_{\mathrm{r}} 97500\right)$, BSA $\left(M_{\mathrm{r}} 68000\right)$, ovalbumin $\left(M_{\mathrm{r}} 43000\right)$ and $\alpha$-chymotrypsin $\left(M_{\mathrm{r}} 25700\right)$. Proteins were stained with Coomassie Brilliant Blue.

Immuno-blotting. Immuno-blot analysis of proteins transferred from SDS/polyacrylamide gels to nitrocellulose membranes (Towbin et al., 1979; Burnette, 1981) or after direct application of proteins to nitrocellulose membranes in a slot-blot apparatus (Schleicher $\&$ Schuell) was performed according to the procedures accompanying the Bio-Rad immuno-blot [goat anti(rabbit IgG) antibody-horseradish peroxidase conjugate] assay kit. In the case of proteins separated by SDS/polyacrylamide-gel electrophoresis, proteins were electrophoretically transferred from the polyacrylamide slab gel to a nitrocellulose membrane with 25 mM-Tris/

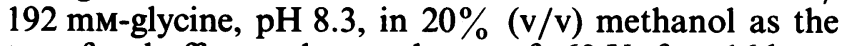
transfer buffer and a voltage of $60 \mathrm{~V}$ for $16 \mathrm{~h}$ at $4{ }^{\circ} \mathrm{C}$. In the case of direct application of proteins to nitrocellulose, $200 \mu \mathrm{l}$ of a protein solution (containing $0.1 \mathrm{ng}$ to $10 \mu \mathrm{g}$ of protein in $0.5 \mathrm{M}$-Tris $/ \mathrm{HCl}$ buffer, $\mathrm{pH} 7.5$, containing $0.1 \mathrm{M}-\mathrm{NaCl}$ and $0.1 \mathrm{~mm}$-EDTA) was applied to each well of the slot-blot apparatus without vacuum. A vacuum was then applied and each 'slot' was washed with approx. $2 \mathrm{ml}$ of Tris-buffered saline $(0.02 \mathrm{M}-\mathrm{Tris} / \mathrm{HCl}$ buffer, $\mathrm{pH} 7.5$, containing $0.5 \mathrm{M}-\mathrm{NaCl}$. Excess protein-binding sites on the nitrocellulose membranes were blocked by incubation for $1 \mathrm{~h}$ at room temperature with Tris-buffered saline containing 3\% $(w / v)$ gelatin. The blocked membranes were incubated with the first antibody or pre-immune IgG in Trisbuffered saline containing $1 \%$ gelatin for $2 \mathrm{~h}$. The membranes were rinsed with water and then incubated with two changes of Tris-buffered saline containing $0.05 \%$ Tween-20 followed by one change of Tris-buffered saline for $20 \mathrm{~min}$ each. The membranes were then incubated with the second antibody, a 1:2000 dilution of horseradish-peroxidase-conjugated goat anti-(rabbit IgG) antibody (Bio-Rad Laboratories) in Tris-buffered saline containing $1 \%$ gelatin for $1 \mathrm{~h}$. The membranes were rinsed after incubation of the second antibody and 

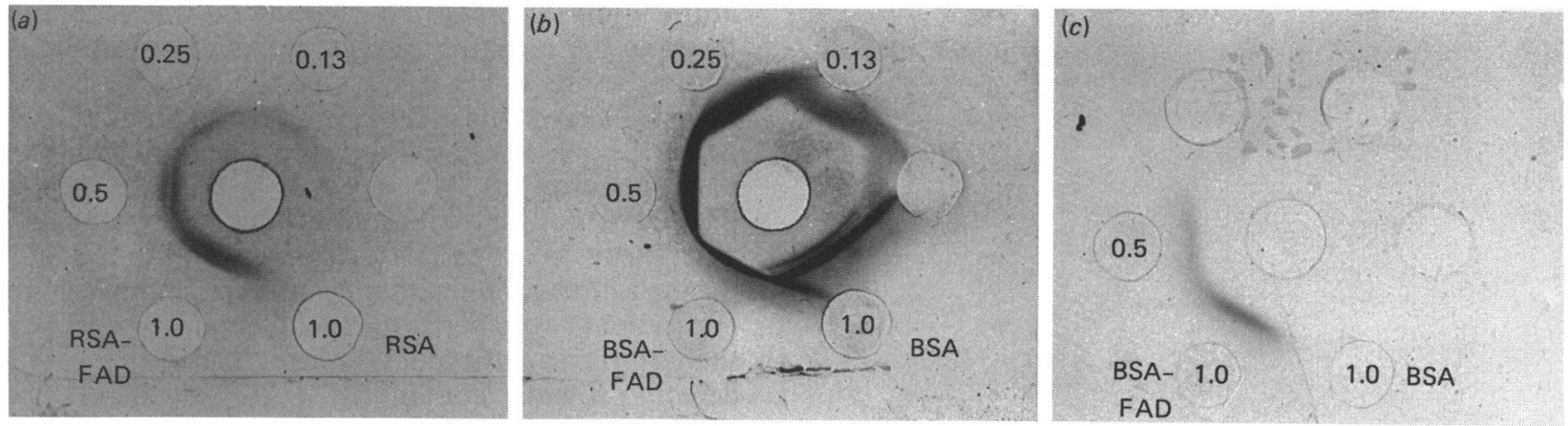

Fig. 1. Immunodifiusion of anti-FAD serum and IgG fraction

The centre wells contained anti-FAD serum collected at 6 weeks from the initial toe-pad injection $(a$ and $b)$ and BSAagarose-affinity-purified anti-FAD IgG $(c)$. The peripheral wells contained the indicated concentrations $(\mathrm{mg} / \mathrm{ml})$ of antigen: BSA, bovine serum albumin; BSA-FAD, 6-AH-FAD conjugated to BSA; RSA, rabbit serum albumin; RSA-FAD, 6-AH-FAD conjugated to RSA. In each case BSA or RSA is present in only one well; dilutions of BSA-FAD or RSA-FAD were placed in the peripheral wells.

subsequently incubated in horseradish peroxidase colour development medium until blue bands appeared. This development solution was prepared by mixing $30 \mathrm{mg}$ of horseradish peroxidase colour development reagent (4-chloro-1-naphthol) (Bio-Rad Laboratories), dissolved in $10 \mathrm{ml}$ of methanol, with $50 \mathrm{ml}$ of Tris-buffered saline containing $40 \mu \mathrm{l}$ of $30 \%$ (v/v) $\mathrm{H}_{2} \mathrm{O}_{2}$ immediately before use. Colour development was terminated by rinsing the membranes with distilled water. The stained membranes were incubated with $50 \%$ (v/v) glycerol for approx. $10 \mathrm{~min}$, blotted dry and stored under clear plastic film.

\section{RESULTS}

\section{Preparation and characterization of antigen}

The coupling of a specific ligand to a suitable immunogenic carrier protein, such as BSA, has become an established method of eliciting antibodies to a desired ligand. Immunization of host animals with BSA-FAD conjugates with an average stoichiometry of one FAD molecule bound per BSA molecule and examination of the subsequent sera failed to reveal the production of IgG molecules directed against flavin as determined by Ouchterlony immunodiffusion. In contrast, use of the 6-AH-FAD derivative, which interposes a long hydrocarbon chain between the functional, reactive, amino group and the adenine moiety, facilitated the preparation of a BSA-flavin derivative that contained an average of four molecules of FAD per molecule of BSA. A similar stoichiometry was observed on spectroscopic analysis of the RSA-6-AH-FAD conjugate.

\section{Characterization of the antibodies}

Sera were monitored for antibody content by Ouchterlony double-diffusion analysis and exhibited cross-reactivity to 6-AH-FAD coupled to RSA as shown in Fig. 1. Sera collected from the sixth and seventh week after the primary injection were chosen for characterization. In the initial serum IgG preparation, a significant degree of cross-reactivity was detected against native BSA, indicating a relatively low titre of anti-FAD IgG and suggesting that the major antibody determinants were due to the immunogenic carrier protein. To decrease the amount of these non-specific antibodies, the

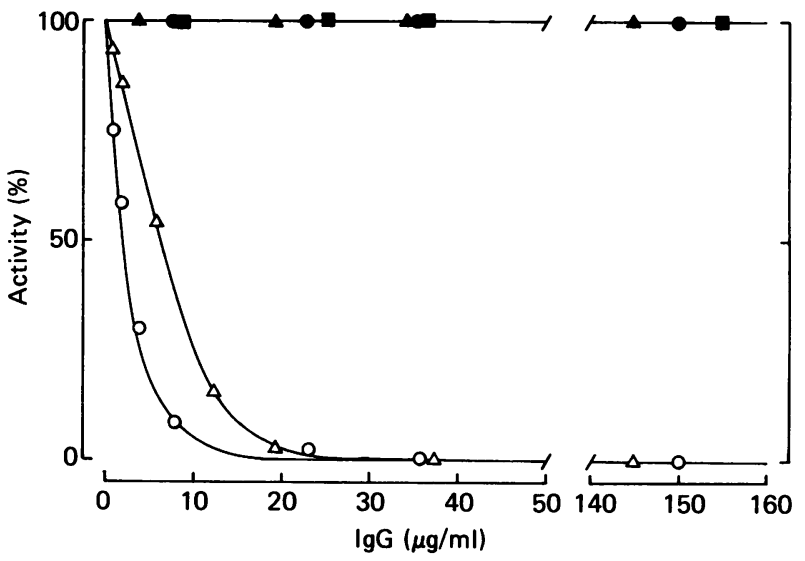

Fig. 2. Effects of purified anti-FAD IgG on the activities of various flavin-containing enzymes

The individual flavoproteins were incubated for $10 \mathrm{~min}$ in 0.05 m-potassium phosphate buffer, $\mathrm{pH} 7.8$, containing $0.1 \mathrm{M}-\mathrm{NaCl}$ in the absence and in the presence of purified anti-FAD IgG at the indicated concentrations, and residual enzyme activity remaining was assayed as described in the Materials and methods section: $\square$, succinate dehydrogenase; $\boldsymbol{O}$, nitrate reductase; $\mathbf{\Delta}$, xanthine oxidase. Nitrate reductase $(O)$ and xanthine oxidase $(\triangle)$ were incubated with purified IgG antibodies elicited against the isolated proteins under similar conditions. Activities are expressed as percentages of control samples incubated in the presence of pre-immune IgG.

IgG fraction was chromatographed on a BSA-agarose affinity column to remove the high-affinity anti-BSA antibodies. This purified IgG fraction was used for all subsequent experiments.

The effects of anti-FAD IgG on the catalytic activities of a number of flavin-containing enzymes are shown in Fig. 2. Incubation of purified Chlorella vulgaris NADHlinked nitrate reductase, bovine milk xanthine oxidase and bovine mitochondrial succinate dehydrogenase with increasing concentrations of purified anti-FAD IgG resulted in no detectable decrease in the activity of any of the enzymes compared with control samples incubated 


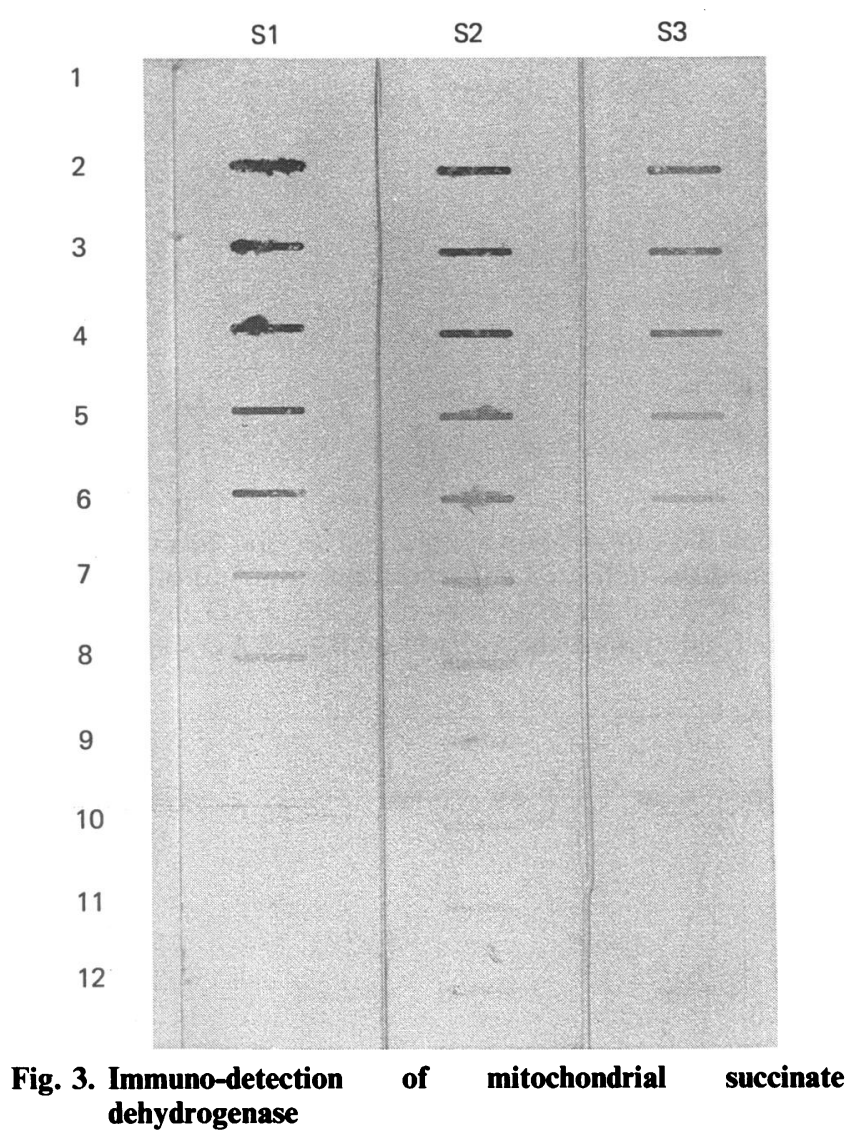

Purified succinate dehydrogenase, at the indicated concentrations of FAD, was transferred to nitrocellulose by using immuno-blotting techniques and incubated with purified anti-FAD IgG, and the bound antibody was detected by using horseradish-peroxidase conjugated goat anti-(rabbit IgG) antibody. Lanes S1-S3, succinate dehydrogenase was incubated with purified anti-FAD IgG $(18.3 \mathrm{mg} / \mathrm{ml}$ in initial undiluted stock solution) at dilutions of $1: 100$ (S1), 1:330 (S2) and 1:1000 (S3). Rows 2-12 represent the following amounts of enzyme added (expressed as total nmol of FAD): row 2, 100; row 3, 30; row 4, 10; row 5, 3 ; row 6,1 ; row $7,0.3$; row $8,0.1$; row $9,0.03$; row 10 , 0.01 ; row $11,0.003$; row $12,0.001$. Row 1 represents a blank with no enzyme added.

either in the absence of or with the inclusion of pre-immune IgG. In contrast, to demonstrate that antibody-antigen interaction would be expected to result in a decrease in enzyme activity, both nitrate reductase and xanthine oxidase samples were incubated with purified anti-(nitrate reductase) IgG and anti-(xanthine oxidase) IgG respectively. In both cases there was a significant decrease in the catalytic activity.

\section{Detection of flavoproteins}

The purified anti-FAD IgG fraction was examined for its ability to cross-react with proteins containing either non-covalently (nitrate reductase) or covalently (succinate dehydrogenase) bound flavin. Purified bovine mitochondrial succinate dehydrogenase was applied to nitrocellulose over a 100 -fold range of protein concentration. The nitrocellulose membrane was incubated with purified rabbit anti-FAD IgG, washed and subsequently incubated with horseradish-peroxidase-conjugated goat anti-(rabbit IgG) antibody. Detection was accomplished by using the peroxidase reaction. As shown in Fig. 3, the antibodies to 6-AH-FAD and the immuno-blot assay system showed this combination could be used to detect as little as $0.1 \mathrm{pmol}$ of succinate dehydrogenase, corresponding to $0.1 \mathrm{pmol}$ of FAD conjugated to protein. In contrast, the immuno-blot technique failed to detect any cross-reactivity between anti-FAD IgG and purified nitrate reductase (Fig. 4). However, limited experiments were performed to examine the specificity of the anti-flavin antibodies with respect to their ability to detect proteins containing FAD covalently bound through a linkage different from the $8 \alpha-N(3)$-histidyl linkage present in succinate dehydrogenase (Walker et al., 1972). The results of immuno-blotting experiments comparing the detection limits of succinate dehydrogenase, $p$-cresol methylhydroxylase and monoamine oxidase are shown in Fig. 4. Different detection limits were observed among the three proteins, corresponding to

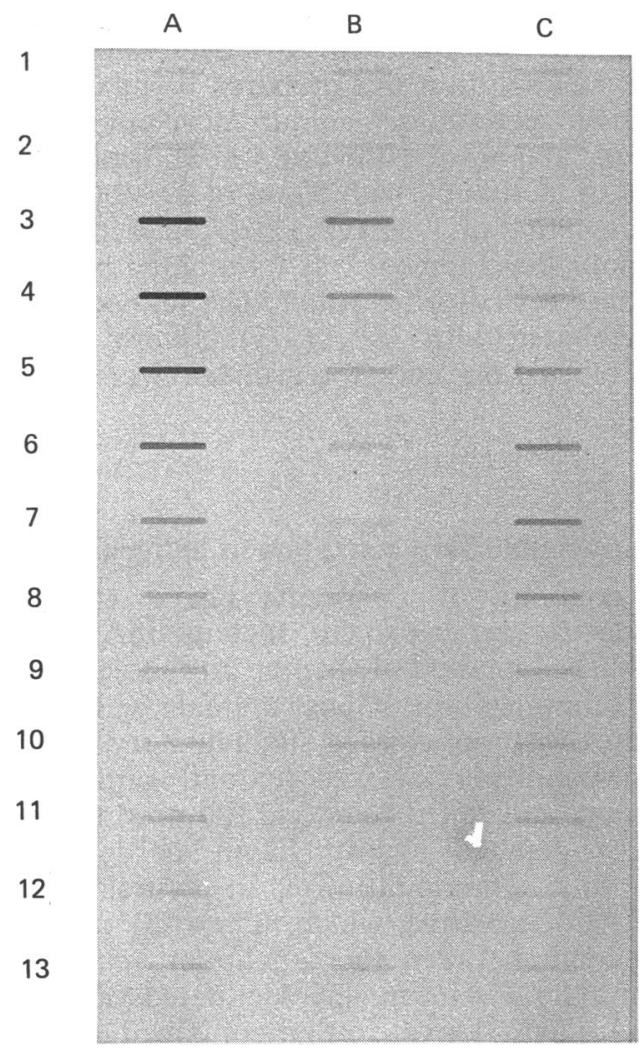

Fig. 4. Immuno-detection of enzymes containing covalently bound FAD

Purified succinate dehydrogenase (lane A), p-cresol methylhydroxylase (lane B) and monoamine oxidase (lane C) were transferred to nitrocellulose by using immunoblotting techniques, at the concentrations of total FAD indicated below, and incubated with purified anti-FAD IgG $(55 \mu \mathrm{g} / \mathrm{ml})$. Bound antibody was detected by incubation with horseradish-peroxidase-conjugated goat anti-(rabbit IgG) antibody. The amounts of enzyme added (expressed as total nmol of FAD) were: row 3, 100; row 4,30 ; row 5,10 ; row 6,3 ; row 7,1 ; row $8,0.3$; row $9,0.1$; row $10,0.03$; row $11,0.01$; row $12,0.003$; row $13,0.001$. Row 1 represents a control with no enzyme added, and row 2 corresponds to the addition of purified nitrate reductase (100 nmol of FAD per well). 


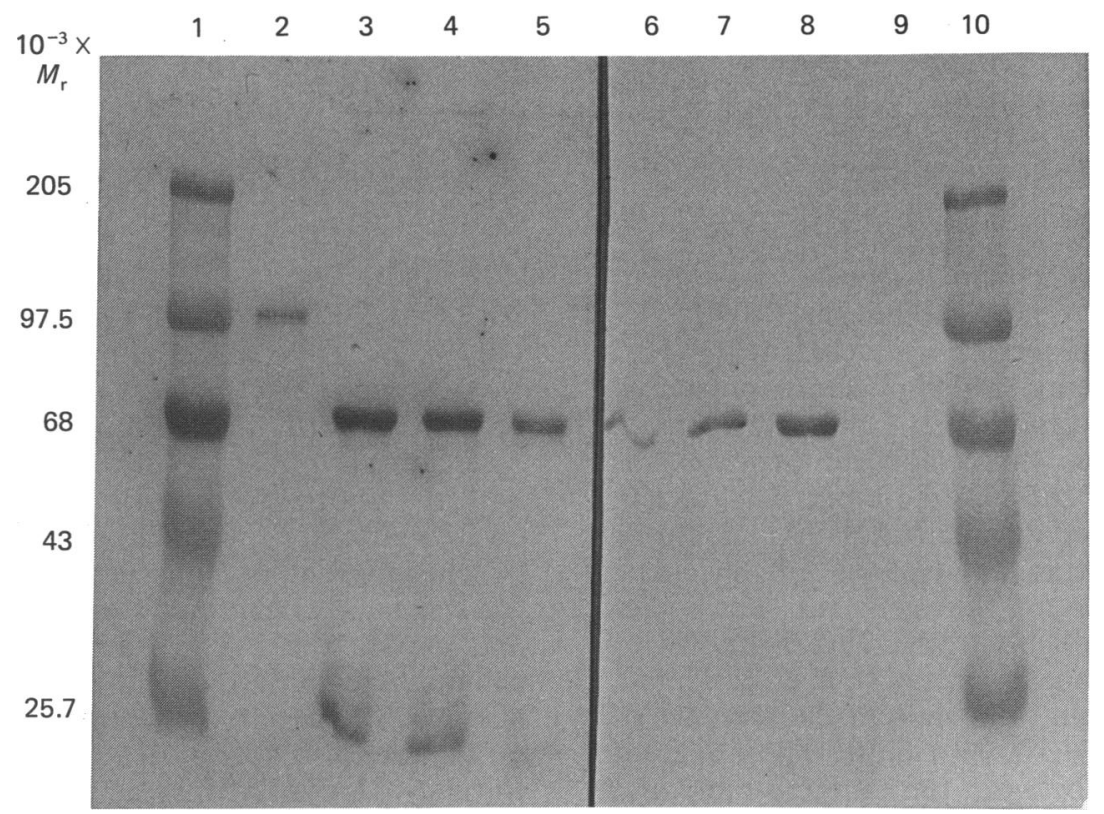

Fig. 5. SDS/polyacrylamide-gel electrophoresis of succinate dehydrogenase and immuno-detection of flavin-containing subunits

Purified succinate dehydrogenase (lanes 3-8) and nitrate reductase (lanes 2 and 9) were subjected to SDS/polyacrylamide-gel electrophoresis, transferred to nitrocellulose and either stained for total protein (lanes 2-5) or incubated with anti-FAD IgG (lanes 6-9) and examined for binding by anti-FAD IgG by using horseradish-peroxidase-conjugated goat anti-(rabbit IgG) antibody. Lanes 2 and 9 correspond to the application of $1 \mu \mathrm{g}$ of total protein, lanes 3 and 8 to $5 \mu \mathrm{g}$ of total protein, lanes 4 and 7 to $2.5 \mu \mathrm{g}$ of total protein and lanes 5 and 6 to $1.25 \mu \mathrm{g}$ of total protein. Lanes 1 and 10 correspond to pre-stained protein standards of the indicated $M_{\mathrm{r}}$ values.

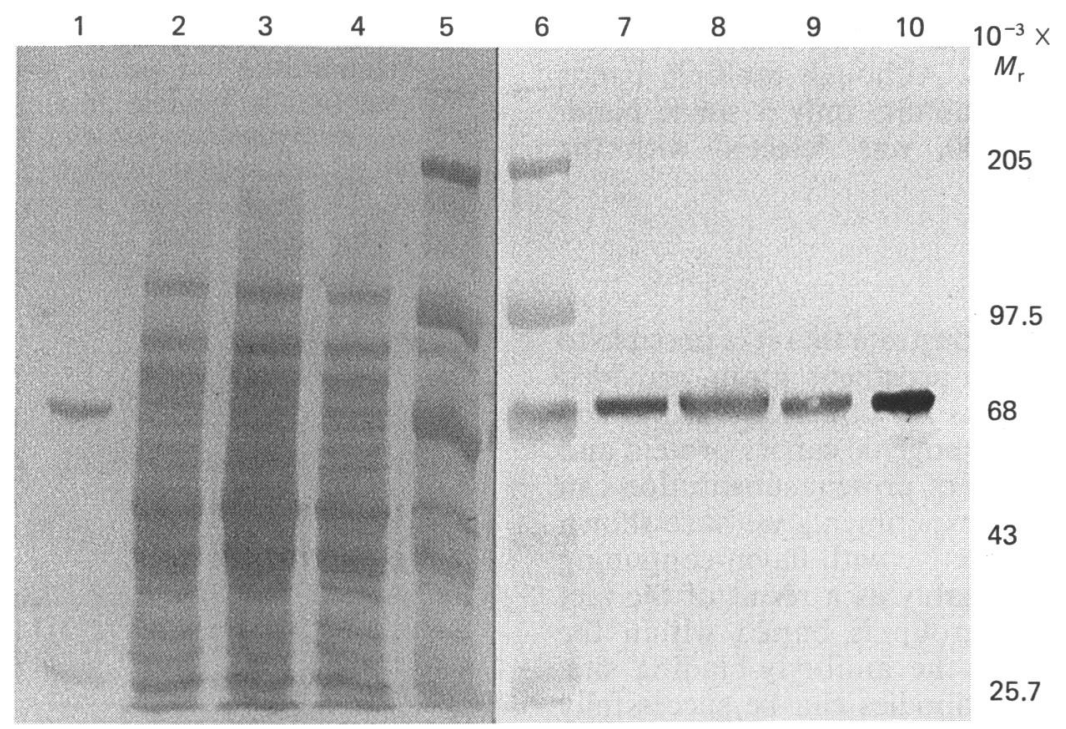

Fig. 6. SDS/polyacrylamide-gel electrophoresis of heart mitochondria and the immuno-detection of flavin-containing proteins

Isolated bovine heart mitochondria were subjected to SDS/polyacrylamide-gel electrophoresis, transferred to nitrocellulose and either stained for total protein (lanes 1-4) or incubated with anti-FAD IgG (lanes 7-10) and examined for binding by anti-FAD IgG by using horseradish-peroxidase-conjugated goat anti-(rabbit IgG) antibody. Lanes 1 and 10 correspond to the application of $2 \mu \mathrm{g}$ of purified succinate dehydrogenase, and lanes 2 and 9 , lanes 3 and 8 and lanes 4 and 7 correspond to the application of $5 \mu \mathrm{g}, 10 \mu \mathrm{g}$ and $20 \mu \mathrm{g}$ of total mitochondrial protein respectively. Lanes 5 and 6 correspond to pre-stained protein standards of the indicated $M_{\mathrm{r}}$ values.

differentially stained bands, even though the proteins were applied at equivalent flavin concentrations. Monoamine oxidase, which contains FAD bound via an $8 \alpha-S$-cysteinyl linkage (Kearney et al., 1971), was detected at concentrations directly comparable with those of succinate dehydrogenase ( $8 \alpha-N$-histidyl-FAD), whereas $p$-cresol methylhydroxylase, which contains an $8 \alpha$-O-tyrosyl linkage (McIntire et al., 1980), was detected only at higher concentrations. Note that the apparent decrease in binding of the anti-FAD IgG to monoamine 
oxidase at high concentrations is due to inhibition of protein binding to the nitrocellulose by glycerol used to stabilize the protein during storage. This effect is lost on subsequent dilution of the samples.

The antibodies to the flavin prosthetic group were also used to detect proteins containing covalently bound FAD after fractionation by SDS/polyacrylamide-gel electrophoresis. Succinate dehydrogenase was heatdenatured $\left(3 \mathrm{~min}\right.$ at $\left.100{ }^{\circ} \mathrm{C}\right)$ in the presence of $\operatorname{SDS}(5 \%$, $\mathrm{w} / \mathrm{v}$ ) and 2-mercaptoethanol $(0.5 \mathrm{M})$ in $0.05 \mathrm{M}$-Tris/HCl

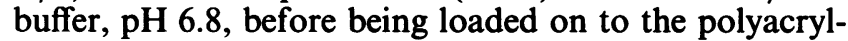
amide gel. After electrophoresis and transfer to nitrocellulose membrane, the labelled protein was detected as described for the immuno-blots. As shown in Fig. 5, antibodies directed against 6-AH-FAD could be used to detect as little as $1.25 \mu \mathrm{g}$ of succinate dehydrogenase applied to the gel, the antibodies detecting only the large subunit, $M_{\mathrm{r}} 70000$, known to contain the FAD prosthetic group (Davis \& Hatefi, 1971), whereas the protein stain showed the presence of both large and small $\left(M_{\mathrm{r}} 30000\right)$ units. The apparent difference in sensitivity between the immuno-blots and SDS/polyacrylamide-gel-electrophoresis patterns may reflect the efficiency of protein transfer from SDS/polyacrylamide gels to the nitrocellulose membrane. The anti-FAD antibodies could also be used to detect protein bands containing covalently bound flavin in crude enzyme preparations. Heart mitochondria were isolated, subjected to SDS/polyacrylamide-gel electrophoresis and transferred to nitrocellulose. The nitrocellulose was then either stained for total protein or incubated with anti-FAD antibody followed by goat anti-(rabbit IgG)-horseradish peroxidase conjugate and horseradish peroxidase staining (Fig. 6). Although multiple bands were revealed by protein staining, only a single band, corresponding to $M_{\mathrm{r}} 70000$, was detected with the antibody.

\section{DISCUSSION}

The preceding results demonstrate that it is possible to elicit antibodies to a protein prosthetic group provided that a suitable method exists for coupling the purified prosthetic group to an immunogenic carrier protein and that sufficiently high degrees of protein substitution can be obtained. In the current experiments we have shown these antibodies to be unreactive with flavin-containing enzymes in solution, presumably as a result of the fact that the flavin prosthetic group is buried within the protein and inaccessible to the antibody-binding site. However, the anti-FAD antibodies can be successfully used to detect denatured proteins containing covalently bound flavin after immobilization on nitrocellulose, and these antibodies exhibit some degree of specificity with respect to the nature of the flavin-protein linkage. These experiments have demonstrated that immuno-blotting techniques can be used to detect a covalently bound protein prosthetic group, such as FAD, at the picomole level. This provides a highly specific and extremely sensitive procedure for the detection of proteins, or protein subunits, containing a covalently bound prosthetic group at a level of sensitivity that far exceeds that which can be detected by visible-region or fluorescence spectroscopy.

The limited experiments performed with flavoproteins containing FAD bound via linkages differing from the
$8 \alpha-N(3)$-histidyl linkage found in succinate dehydrogenase suggested that the antibodies, though crossreacting with the flavin chromophore present in p-cresol methylhydroxylase and monoamine oxidase, exhibited some degree of specificity with respect to the type of flavin-protein linkage. The FAD in monoamine oxidase, which is bound via an $8 \alpha-S$-cysteinyl linkage (Kearney et al., 1971), was recognized with a sensitivity comparable with that for succinate dehydrogenase, but, in contrast, the FAD in $p$-cresol methylhydroxylase, which is present as an 8 8 -O-tyrosyl linkage (McIntire et al., 1980), was recognized with a significantly decreased sensitivity. These results may suggest that the level of cross-reactivity with the antibody could be influenced by the mode of co-ordination of the flavin moiety to the protein. These conclusions require the assumption that different proteins are sufficiently denatured upon binding to nitrocellulose and expose the FAD prosthetic group to equivalent extents. Any variation in the degree of unfolding could also result in apparent changes in antibody specificity.

We were also able to demonstrate that the antibodies to the 6-AH-FAD could be used to identify specifically proteins, or protein subunits, containing covalently bound flavin within complex protein mixtures after separation by SDS/polyacrylamide-gel electrophoresis. This approach should be particularly advantageous for identifying and analysing proteins containing covalently bound FAD or other flavin derivatives in complex protein systems.

We are indebted to Dr James Albarella and Dr. David Morris of the Ames Division, Miles Laboratories, for generously donating 6-AH-FAD and 6-AH-FAD-BSA conjugate and their interest in this research. We are further indebted to Dr. William McIntire for generously donating p-cresol methylhydroxylase and to Dr. Walter Weyler for the sample of monoamine oxidase. This work was supported by Grant 84-CRCR-1-1404 from the U.S. Department of Agriculture and Grants GM 32696 and ML 16251 from the National Institutes of Health.

\section{REFERENCES}

Avis, P. G., Bergel, F. \& Bray, R. C. (1955) J. Chem Soc. $1100-1103$

Baginsky, M. L. \& Hatefi, Y. (1969) J. Biol. Chem. 244, 5313-5318

Barber, M. J. \& Siegel, L. M. (1982) Biochemistry 21, 1638-1647

Burnette, W. N. (1981) Anal. Biochem. 112, 195-203

Davis, K. A. \& Hatefi, Y. (1971) Biochemistry 10, 2509-2516

Eichler, D. C. \& Glitz, D. G. (1974) Biochim. Biophys Acta 335, 303-317

Hatefi, Y. (1978) Methods Enzymol. 53, 27-35

Howard, W. D. \& Solomonson, L. P. (1982) J. Biol. Chem. 257, 10243-10250

Humphries, G. M. K. \& McConnell, H. M. (1976) Biophys. J. 16, 275-277

Kearney, E. B., Salach, J. I., Walker, W. H., Seng, R. L., Kenney, W., Zeszotek, E. \& Singer, T. P. (1971) Eur. J. Biochem. 24, 321-327

Kovac, C., Pflumm, M., Fleischman, M. \& Beychok, S. (1985) Fed. Proc. Fed. Am. Soc. Exp. Biol. 44, 1327

Laemmli, U. K. (1970) Nature (London) 227, 680-685

Lowry, O. H., Rosebrough, N. J., Farr, A. L. \& Randall, R. J. (1951) J. Biol. Chem. 193, 265-275

McIntire, W., Edmondson, D. E., Singer, T. P. \& Hopper, D. J. (1980) J. Biol. Chem. 255, 6553-6555

Morris, D. L. \& Buckler, R. T. (1983) Methods Enzymol. 92, 413-427 
Ouchterlony, Ö. (1968) Handbook of Immunodiffusion and Immunoelectrophoresis, Ann Arbor-Humphrey Science Publishers, Ann Arbor

Palacios, R., Palmiter, R. D. \& Schimke, R. T. (1972) J. Biol. Chem. 247, 2316-2321

Solomonson, L. P., Lorimer, G. H., Hall, R. L., Borchers, R. \& Bailey, J. L. (1975) J. Biol. Chem. 250, 4120-4127

Received 28 May 1986/19 August 1986; accepted 13 October 1986
Towbin, H., Staehelin, T. \& Gordon, J. (1979) Proc. Natl. Acad. Sci. U.S.A. 76, 4350-4354

Van Vunakis, H. \& Langone, J. J. (eds.) (1980) Methods Enzymol. 70

Walker, W. H., Singer, T. P., Ghisla, S. \& Hartmann, U. (1972) Eur. J. Biochem. 26, 279-289

Whitby, L. G. (1953) Biochem. J. 54, 437-439 